\title{
Impacts of staff demographics on complaint management behaviour in five-star hotels in Dubai
}

\author{
Parin Parikh and Christopher S. Dutt \\ The Emirates Academy of Hospitality Management, Dubai, United Arab Emirates
}

\begin{abstract}
Purpose - A continuous issue which plagues all service businesses is the process of handling complaints. Whilst the topic has been relatively well explored, extant literature has failed to fully explore how staff demographics influence the methods in which they manage complaints.

Design/methodology/approach - A qualitative approach was adopted with semi-structured interviews. A purposeful sample was selected, inviting managers from hotels in Dubai to share their views on factors affecting the complaint management process, including the impact of staff demographics.

Findings - Staff demographics were found to have an impact on staff's approach to handle complaints. However, participants generally felt that, with sufficient experience, the impact of many of these influences would be negated.

Originality/value - Literature on complaint management has considered numerous mitigating factors affecting the complaint management process. The impact of staff demographics on how they receive and respond to complaints has not been thoroughly explored.
\end{abstract}

Keywords Complaint management, Quality, Demographics, Staff demographics

Paper type Research paper

\section{Introduction}

The handling of complaints remains a vital, yet under-researched element of customer experience management (Chan et al., 2017; Krishna et al., 2011). The fast-paced and exponential growth of the hotel industry has made it extremely important for hotels to increase guest retention to remain operational and profitable (Singh et al., 2016). Given growing competition, increasing customer expectations (Cai and Chi, 2018) and the fallout from the COVID-19 pandemic, the need for hotels to retain guests and boost customer satisfaction has taken on new importance (Farazad, 2020). Studies have shown a correlation between guests' satisfaction with the management of their complaints and their intentions to become loyal to a brand (Cheng and Lam, 2008). In fact, according to the service recovery paradox, well-handled complaints can improve the postrecovery satisfaction and loyalty of customers and be even higher than those who have not faced any problems (Maxham and Netemeyer, 2002; Ok et al., 2007; Smith and Bolton, 1998).

Research also suggests that service failure gives service providers an opportunity to enhance the relationship with their customers through better understanding their needs (Krishna et al., 2014). Therefore, building relationships is essential for hotels as healthy customer relationships can provide hotels with more knowledge about their customers (Krishna et al., 2014), promote loyalty, build a competitive advantage, (Kandampully et al., 2018)

(C) Parin Parikh and Christopher S. Dutt. Published in International Hospitality Review. Published by Emerald Publishing Limited. This article is published under the Creative Commons Attribution (CC BY 4.0) licence. Anyone mayreproduce, distribute, translate and create derivative works of this article (for both commercial and noncommercial purposes), subject to full attribution to the original publication and authors. The full terms ofthis licence may be seen at http://creativecommons.org/licences/by/4.0/ legalcode

The authors would like to extend their thanks to the participants, manuscript reviewers and editors for their assistance and support in this research and publication.
Complaint

management

behaviour

Received 4 March 2021 Revised 18 April 2021 Accepted 31 May 2021

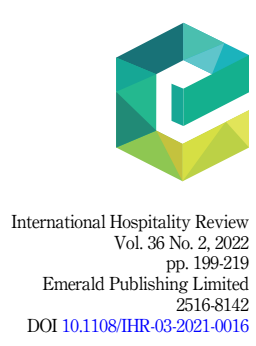


IHR

36,2

\section{0}

and encourage more spending, which are more cost-effective than attracting new guests (Krishna et al., 2011).

Previous studies have emphasised the need to establish complaint management and service recovery processes within firms (Bambauer-Sachse and Rabeson, 2015; Estelami, 2000) and others have explored the role of customer's demographics on their perceptions of the complaint management experience (Chung-Herrera et al., 2010; Gruber et al., 2009). However, none have evaluated the impacts of the service provider's demographic factors on their complaint-handling behaviours. Current literature suggests that the perceived nature of complaints made by customers affects the way in which complaint handlers react, for example, employees who perceive complaints to be aggressive tend to respond in a "motivated close-minded" way (Traut-Mattausch et al., 2015). Additionally, a study conducted on the behaviours which are most valued by male and female complainants revealed that females valued emotional connections when their complaints were being handled as opposed to men, who demonstrated a greater desire for prompt solutions (Gruber et al., 2009). Evidently, when there are these differences in the complainants' expectations, it can be hypothesised that the complaint-handlers would react to complaints based on their perceptions of the complainant and complaint.

The hospitality industry, whose workforce is demographically varied, aims to be consistent in terms of the experience they provide to guests (Chung-Herrera et al., 2010; Sarpong, 2016). However, greater empowerment of front-line employees means that employees determine an appropriate response to a complaint based on their perception of the complainant and complaints (Ogbeide et al., 2017). This has shown a negative correlation with consistency, as employee demographic differences can lead to different methods of handling similar issues (Chung-Herrera et al., 2010).

While the impact of customers' demographic differences have been explored, there is a lack of research on the impact of complaint-handlers' demographic factors in terms of the ways complaints are handled. Despite understanding how customers' demographics impact the way in which they perceive service recovery efforts, if there is no understanding on how the service provider's demographics impact complaint management, a mismatch in the service recovery process is possible. This lack of knowledge limits the understanding and applicability of complaint management processes or training programs in hotels. In order to implement a strategy which allows empowerment within employees and consistency in service recovery and complaint management, it is important to understand if and how demographic differences actually affect complaint management behaviour.

This exploratory study and its results have potential to play a role in both practical and theoretical scenarios. Practically, hotels can use the results of this study to implement informed training programs which will improve the consistency of service recovery processes in hotels, increasing the possibility of turning around service failure and reducing the negative impact of the failure on guest experience and hotel image. Theoretically, understanding the impact of any demographic influence can be studied to prepare future leaders for the best way to handle complaints in the service industry, not just limited to the hotel industry. Finally, understanding the impact of demographics on the behaviour can be used as a basis for further research to provide insight into the behaviours of individuals when in a conflict situation and how their demographics impact the way in which they handle situations. The research therefore addresses the question; "What are the impacts of staff demographics on complaint management processes in five-star hotels?"

The research will start with an exploration of the prevailing literature on the topic of complaint management and the complaint management process in hotels, before considering how the results of the study contribute to both industry practice and theoretical understanding. 


\section{Literature review}

\section{Complaint management}

The term "complaint" can be defined in several ways. According to Sturman et al. (2011, p. 165), complaints are "social altercations which are initiated to adjust the expectations and outcomes of a service experience". Other authors define complaints as the "expression of pain, displeasure, annoyance or dissatisfaction towards a company due to an unsatisfactory or problematic experience" (Ogbeide et al., 2017, p. 2), possibly with the aim of receiving some compensation (Chan et al., 2017).

The management of these complaints can be considered a systematic response from the organisation, or an individual who represents the organisation, to re-satisfy customers, recover service failures and restore or strengthen the relationship between the customer and the organisation (McCole, 2004; Ogbeide et al., 2017; Susskind, 2010). The term "complaint management", too, lacks a universal definition; however for the purpose of this study, it can be defined as the response of an individual or an organisation to a customer complaint (Ogbeide et al., 2017). Complaint management, which includes service recovery, is a frequently over-looked aspect in hotels (Krishna et al., 2011). The high level of interaction between employees and hotel guests often makes it likely for service failures to occur (Gelbrich et al., 2015; Lewis and McCann, 2004). Despite this, hotels in a competitive setting take little effort to identify what problems guests face, how these problems are solved and the impact of the service recovery efforts on the guest (Lewis and McCann, 2004). Additionally, complaint management trainings are limited and many hotels do not have complaint management systems in their operations (Tag-Eldeen, 2018).

Complaint management is an integral part of a manager's duty, and the process is largely handled by front-line managers, particularly assistant managers, guest services managers or guest relations managers in the front office department (Dinnen and Hassanien, 2011). However, the increase in empowerment has broadened the role of other front-line employees, wherein many front-line employees also handle complaints (Dinnen and Hassanien, 2011; Ogbeide et al., 2017; Zhang and Geng, 2019). Employees are being pushed to handle complaints without forwarding them on to their superiors as studies have shown that welltrained, empowered front-line employees are a key element of an effective complaint management strategy (Dinnen and Hassanien, 2011; Zhang and Geng, 2019). This empowerment drive makes it extremely important to address the gap in research surrounding the impact of staff's demographics on complaint management topic.

\section{Importance of complaint management}

Service failure in the hotel industry is unavoidable due to the subjective nature of services (Krishna et al., 2011; Stone, 2011). A service failure could result in long-term damage to the customer-organisation relationship (McCole, 2004), more wide-spread negatives from negative word-of-mouth, or can, thanks to the service recovery paradox, lead to greater customer satisfaction (Cambra-Fierro et al., 2016; Hart et al., 1990). This relationship is important for organisations as the increased competition makes it vital to maintain and increase guest retention rates (Ogbeide et al., 2017; Singh et al., 2016), which can reflect grater revenues (Cook, 2011). In addition to the increased potential for revenue growth, there are four distinct benefits of effective complaint management for organisations (Stauss and Schoeler, 2004); information, attitude, repurchase and communication.

The information benefit refers to the value obtained from analysing customer complaints to extract otherwise unavailable trends and patterns. This can allow for better root-cause analysis to pre-empt and efficiently handle complaints (McCollough et al., 2000). Without customer complaints, businesses may not be aware of problems or issues which exist, leaving them unable to take corrective action (Taleghani et al., 2011). Furthermore, some guests may not voice their dissatisfaction to the company and instead prefer to change their loyalty to

Complaint management behaviour 
IHR

36,2

other brands or voice their dissatisfaction to friends and family leading to negative word-ofmouth (Dinnen and Hassanien, 2011; Janjua, 2017). The attitude benefit suggests that the customer's change in attitude, from dissatisfied to satisfied, due to effective complaint management can lead to future profits for the firm. This benefit is also highlighted by the service recovery paradox which states that effective handling of a customer complaint may lead to greater satisfaction and loyalty than a customer who did not face a service failure (Michel and Meuter, 2008). This then leads to the third benefit: the repurchase benefit. This aspect further emphasises that repurchases are a distinct benefit for firms, particularly due to the fact that repurchases demonstrate guest loyalty, a factor which has been highlighted as being imperative in the hospitality industry (Stauss and Schoeler, 2004). Finally, the communication benefit highlights the word-of-mouth aspect of effective complaint management. Wherein a lack of corrective action can lead to a downward spiral of guest dissatisfaction and loss of guest loyalty, satisfied customers are likely to engage in positive word-of-mouth, recommend the company to others and hence facilitate the growth of the company's customer base (Stauss and Schoeler, 2004).

Overall, it can be said that successful and effective management of complaints can lead to improved relations between the organisation and the customer, an improvement in the service quality through corrective action, potential for increased guest retention and enhanced revenue for organisations in the service industry (McCole, 2004). This knowledge makes it even more vital to understand the value of appropriate complaint management and how complaints are currently handled.

While hospitality organisations aim to maintain their consistency in service provision, there is a high dependency on their human capital as these are the ones who deliver the experience to guests (Lee and Lee, 2012; Zhang and Geng, 2019). Human capital in the hotel industry is extremely diverse in terms of the demographics present, as this industry is composed of both secondary and primary labour markets (Boella and Goss-Turner, 2013). The subsequent section presents the existing complaint management processes in the service industry.

\section{Complaint management processes}

The hospitality sector is a part of the greater service industry wherein the customer is one of the strongest forces driving change. With their unwillingness to compromise and their freedom in choosing where they spend their money, customer satisfaction is a determinant of the success of a service business (Sujithamrak and Lam, 2005).

Various studies have highlighted the importance of implementing complaint management processes in organisations, particularly in the service industry, in order to avoid misallocation of resources, energy, attention and to encourage the aforementioned four key benefits (Stauss and Schoeler, 2004). In the service industry, research suggests that there are six main factors for organisations to consider when responding to complaints (Davidow, 2003): Timeliness, complaint support, resolution, apology, organisation credibility and organisation attentiveness.

With a multitude of factors which affect the outcome of a complaint management experience, it becomes even more important to establish a clear complaint management processes (Homburg et al., 2010; Phabmixay et al., 2019). Studies suggest that although the importance of service recovery and complaint management is understood, there is little focus on this in organisational practices, which is evident through the lack of policies and practices addressing complaint management (Van Vaerenbergh and Orsingher, 2016). Further emphasising the need for complaint management processes, Phabmixay et al. (2019) propose a complaint management model (Figure 1), which facilitates the standardisation of the above factors through the implementation of three styles of guidelines. 


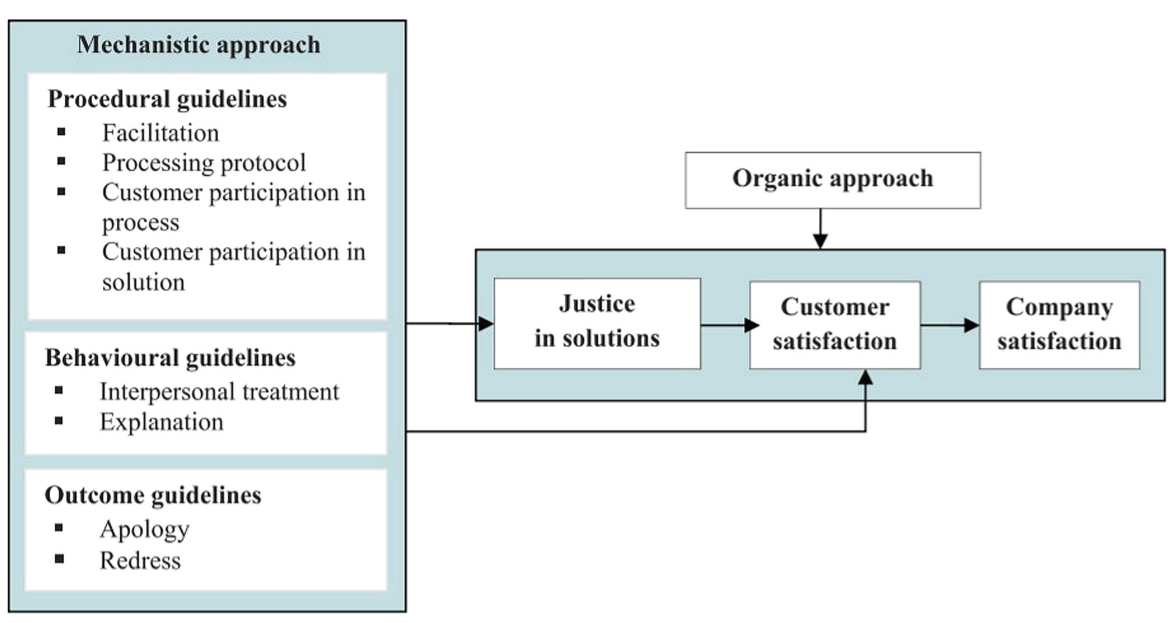

Source(s): Phabmixay et al. (2019)

Figure 1. Proposed model of a standardised complaint management system

The "mechanistic" approach provides procedural, behavioural and outcome-based guidelines. Procedural guidelines refer to the way complaints are received, processed and recorded. Behavioural guidelines inform employees about how to best apply their interpersonal skills and explanations to customers for any service failures. Finally, outcome guidelines define the tangible and intangible compensation that the customer receives as a result of his/her complaint (Phabmixay et al., 2019).

However, this standardised model has been suggested for manufacturing firms, and there is a lack of research focusing on the standardisation of complaint management systems in hospitality, which has the additional complication of heterogeneous service delivery and consumption. In an attempt to understand if and how such a process can be created, it is important to explore how the handling of complaints can vary based upon staff demographics.

\section{Demographics}

Increased globalisation and immigration have changed the nature of the workforce (Chaudhary and Rangnekar, 2017). Particularly in the hospitality sector, the workforce has become extremely diverse and will continue to diversify (Gajjar and Okumus, 2018; Lee and Lee, 2012).

According to Chaudhary and Rangnekar (2017), different demographic groups have different priorities, needs and wants. Studies have shown that demographics play a role in the perceived importance of factors such as key performance indicators (KPIs), rewards and organisational commitment for employees in hotels (Chiang and Birtch, 2008; Sourouklis and Tsagdis, 2013). Additionally, social identity theory, according to Tajfel (2010), states that people belonging to a certain group behave in a certain way. This theory states that individuals define their own identities through belonging to certain social groups (Chattopadhyay et al., 2004; Islam, 2014). These groups can be social categories such as race, gender and workgroup. Moreover, people behave similarly due to the similarities in the qualities, which are attributed by members of that particular category (Chattopadhyay et al., 2004). According to Islam (2014), these identifications work to protect and bolster people's self-identities, and this is often a subconscious phenomenon. 
IHR

36,2

\section{4}

Demographic factors could therefore influence similar groups of people to behave in a certain way. However, there have been critiques surrounding the topic of associating people's behaviours with the demographic group in which they belong (Chung-Herrera et al., 2010). Some of the critical evaluations suggest that attributing behaviours to demographics can be a form of stereotyping, discrimination and favouritism (Chaudhary and Rangnekar, 2017; Chung-Herrera et al., 2010; Lee and Lee, 2012). Despite this, it can be argued that an individual uses his/her demographic factors to fit into certain groups and feel included (Chung-Herrera et al., 2010). Hence, when the individual self-categorises themselves into a group and acts in the same way as that group, this cannot be considered stereotyping. In fact, by understanding how demographics affect human behaviour, firms can better manage diversity (Gajjar and Okumus, 2018). Managing diversity is vital and can be used by hotels and other hospitality organisations to proliferate organisational effectiveness and to ensure that the variation of human capital facilitates the achievement of organisational objectives (Gajjar and Okumus, 2018; Olsen and Martins, 2012).

\section{Empirical context}

The study was conducted in Dubai, one of the seven emirates in the United Arab Emirates (UAE). Tourism is a significant component of Dubai's economy (Newnham and Dutt, 2021), and the destination is famous for its numerous noteworthy attractions, such as the world's "most luxurious hotel" - Burj Al Arab - and the world's tallest building - Burj Khalifah (Dutt and Ninov, 2017). The luxurious hospitality of Dubai is well known and clearly demonstrated by the abundance of five-star hotels in the emirate; of the 712 accommodation establishments in Dubai, nearly 20\% are five-star properties (DTCM, 2021). Even amidst the COVID-19 pandemic, the UAE's tourism sector - led by Dubai - performed well; the UAE recorded the second highest hotel occupancy average globally in 2020, at $54.7 \%$, behind China's $58 \%$ (Rizvi, 2021). Of particular importance for this research on demographic influences on complaint management is the constitution of Dubai's population. Dubai and the UAE is a majority expatriate population, with an estimated $92 \%$ of Dubai's population being expatriate (Dubai Statistics Center, 2021). The population is generally quite young and well educated, with a $60 \%$ of the population under the age of 34, a literacy rate of 97.36 and $36.03 \%$ of the population with a university or post-graduate degree (Dubai Statistics Center, 2021).

\section{Research methodology}

An inductive approach with a subjective ontology and interpretivist epistemology was most appropriate to thoroughly explore and discuss the impact of demographics on complaint management (O'Gorman and MacIntosh, 2016; Schindler, 2019). From the literature review, it is evident that there is a lack of research on this topic which makes it difficult to adopt a research model, which focuses on theories guiding hypotheses and data collection (O'Gorman and MacIntosh, 2016).

A qualitative approach was deemed most suitable for this study as it facilitated a deeper understanding of and insight into this exploratory topic (Bryman and Bell, 2015; Creswell and Creswell, 2018; Jennings, 2010; O'Gorman and MacIntosh, 2016). Specifically, semi-structured interviews were conducted with 11 front office managers in five-star hotels in Dubai. These interviews facilitated an in-depth understanding on the topic as they consisted of thematic open-ended questions which allowed for discussion and critical reflection on the interviewee's end (Galletta, 2016). The interviews were conducted with guiding questions however probing questions were asked to clarify uncertainties (Cooper and Schindler, 2008).

As in-person face-to-face interviews were not possible due to the COVID-19 circumstances, VoIP software was used, such as Zoom and Microsoft Teams, to mimic the interview setting. 
However, the main benefit of face-to-face interviews, which is the ability to read the interviewees body language and non-verbal attributes in reaction to a question, was still possible through the virtual interviews.

A purposeful sampling approach was adopted, which allowed participants to be sourced who could offer the most value to the study. The participants deemed most appropriate were approached through mediums such as LinkedIn, snowballing and personal contacts. Initially, a total of 15 individuals were contacted, with 11 providing consent for to be interviewed. Saturation was noticed after the 10th interview, with the 11th confirming saturation. This sample size allowed the data to be discussed and examined in detail to maximise understanding on the topic (Nam et al., 2020). Participants represented front office management team members from 11 hotels, covering eight different hotel brands in Dubai. A small variety of different hotels were desirable to ensure that the impact of any company policy on complaint management would be detected. It was beyond the scope of this study to explore impacts between different department approaches of handling complaints and potential demographic issues. Therefore, as one of the main customer-facing departments that sees guests as they arrive and depart, front-office was chosen as the main department of interest. Participants were selected based upon their position and to provide a variety of different hotels to partially control for the impact of company policy, not demographic traits they represented.

\section{Research instrument}

The questions for the interview were designed in a way which allowed the interviewee to delve deeper into the topic of complaint management in a gradual manner. The initial questions attempted to engage the interviewee into the topic of complaint management and its importance in hotel operations. The questions which followed, enticed the interviewee into reflecting on the impacts of demographic factors on complaint management behaviour as once the initial questions had warmed the respondent up to the topic, the conversation was much more reflective and free flowing. The final questions attempted to understand how the demographics of individuals impacted complaint management behaviour. Finally, the respondents were asked about other factors which they deemed contributory to the complaint management process and about any recommendations they could provide on how hotels could improve complaint management processes. Given the lack of existing research on this topic and the exploratory nature of this study, the interview questions and sampling methods did not focus on specific demographic traits. Instead, questions encouraged a variety of participants to consider how demographics influenced their and their team's approach to handling complaints. To provide greater insight and detail, certain demographic characteristics popular in customer-based research were asked as probing questions later in the interview. This therefore allowed participants to freely discuss their thoughts on the impact of staff demographics before probes were offered on specific demographic traits that have found relevance in research on customer complaint behaviour. Such traits included gender (Chung-Herrera et al., 2010; Gruber et al., 2009; McColl-Kennedy et al., 2003), age (Chung-Herrera et al., 2010; Kasabov and Hain, 2014), education levels (Ngai et al., 2007; Sujithamrak and Lam, 2005) and nationality (Defranco et al., 2005; Emir, 2011; Ngai et al., 2007; Prayag and Ryan, 2012).

\section{Data collection}

All interviews were conducted online through VoIP software, Zoom, which allowed for the interviews to be recorded. In addition, the transcription software Otter was used as it allowed for transcription to be done quickly, for free and accurately with its Artificial Intelligence (AI) technology (Nam et al., 2020). The average duration of each interview was 47 min with the shortest interview being $31 \mathrm{~min}$ and the longest being $1 \mathrm{~h}$ and $31 \mathrm{~min}$.
Complaint management behaviour 
IHR

36,2

Prior to the interview process, in order to ensure that the interview questions were appropriate, a pilot interview was conducted. This allowed the researcher to confirm the validity of the questions. The pilot study also allowed the researcher to assess the functionality of the VoIP software and the transcription software. After the pilot study was conducted, there was only one change made, which was the specification of "staff demographics" in the demographic-centric. This was done to ensure that the responses from the interviewees revolved around the impacts of the complaint handler's demographics on their complaint management behaviour as opposed to the demographics of complainers on the process.

\section{Data analysis}

Data were analysed following a thematic analysis approach, which identified, analysed, organised and reported themes found within the data (Nowell et al., 2017). This method was used due to its well-structured approach to organising data that are flexible and easy to implement (Braun and Clarke, 2006). Emerging and pre-existing themes were sought from the transcripts and revised during multiple re-readings and revisions to ensure a complete and clear understanding of participant's perceptions of the impact of demographics on complaint behaviour. Furthermore, themes were synthesised into new categories, where applicable, to provide a more consolidated meaning (Saldaña, 2016). For example, when participants were asked how complaints were currently handled in their hotels, participants described "training", "supervisor training" and "walk-throughs of standard operating procedures (SOPs)", which were collectively synthesised into the theme of "training". The data analysis tool, QDA Miner was used to simplify and quicken the pace of the data analysis as it allowed the researcher to identify and code without the use of paper-based methods or other nonanalysis specific software (Nam et al., 2020).

\section{Research findings}

Demographic profile

All participants were asked certain demographic questions in order to build their demographic profile, with the results visible in Table 1 . While the sample was varied, this is reflective of the constitution of the UAE population and hotel labour market; participants were not encouraged to speak about complaint management from their perspective as a representative of their demographic.

Participants were first asked more contextual questions, referring to what they understood by complaint management and its implications. Here, themes emerged referring to a definition, the reason for complaints and the impacts complaints have on a business.

Definition of complaint management. Most participants believed that their role in complaint management moved beyond the "basic handling [of] guest complaints" (P1) to also cover evaluating the genuineness of the complaint:

....it's very, very important to first understand whether it's an actual complaint or whether it's just, you know, rubbish. (P7)

Another key element of complaint management was identifying guest needs, with four participants specifically addressing this requirement:

...handling a complaint in a proper way, understanding the guest needs and, um, meet their expectation or request and turn the guest experience around. (P6)

Nine of eleven participants believed that complaint management was about solving problems. P3 mentioned that it is all about "solving guest issues and problems," and "you have to bring up solutions”. (P10) 


\begin{tabular}{|c|c|c|c|c|c|c|c|}
\hline & Gender & Age & Nationality & Education levels & Years in hospitality & Current position & \\
\hline $\mathrm{P} 1$ & M & $25-30$ & French & Bachelor's degree & 10 & Assistant manager & iour \\
\hline $\mathrm{P} 2$ & $\mathrm{M}$ & $35-40$ & Indian & $2 \mathrm{x}$ bachelor's degree & 16 & Duty manager & \\
\hline P3 & $\mathrm{F}$ & $40-45$ & Italian & Master's degree & 7 & Duty manager & \\
\hline $\mathrm{P} 4$ & $\mathrm{~F}$ & $30-35$ & Russian & Bachelor's degree & 5 & Assistant manager & \\
\hline P5 & $\mathrm{F}$ & $30-35$ & Ukrainian & Master's degree & 10 & Front office manager & \\
\hline $\mathrm{P} 6$ & $\mathrm{~F}$ & $30-35$ & Chinese & Bachelor's degree & 10 & Operations manager & 207 \\
\hline P7 & M & $25-30$ & Indian & Bachelor's degree & 7 & Assistant manager & \\
\hline P8 & $\mathrm{F}$ & $20-25$ & Indian & Bachelor's degree & 2 & Assistant manager & \\
\hline P9 & $\mathrm{F}$ & $30-35$ & Malawian & Advanced diploma & 8 & Team leader & Table 1. \\
\hline P10 & M & $20-25$ & Indian & Bachelor's degree & 3 & Team leader & phic profile of \\
\hline P11 & $\mathrm{F}$ & $30-35$ & Lebanese & Bachelor's degree & 13 & Front office manager & interviewees \\
\hline
\end{tabular}

Reasons for guest complaints. Of 11 participants, eight believed that guests complain in order to receive some sort of compensation and that they are looking to just receive something for free by complaining:

...they just wanted to get something free like compensation that always comes from saying things are not satisfactory... (P1)

A total of eight participants also mentioned that guest expectations not being met also led to guests complaining:

... when they don't really, when they don't really get the kind of service, which they expect from a four-star or a five-star hotel, they really feel bad (P10).

Impacts of guest complaints. Both positive and negative impacts of guest complaints were identified by interviewees. In total, six participants believed that guest complaints can impact the hotel's operation.

So, imagine that they work eight hours a day, they would have angry guests, yeah, complaining guests, like they cannot handle it, it was exaggerated, manager was not available and then they just. . . all they've done is. . . the day is gone already, I mean, like, in the way that they can't recover from this, they cannot calm down as a colleague right. And they will put it to the other guests. They can give the mixed information they, they tend to do more mistakes when they are, you know, in the [mood] because they cannot reply back to the guests [so] they are going to be angry inside. So, they tend to the more mistakes, give incorrect information. (P4)

Guest satisfaction and the opportunity to satisfy guests was another impact identified by five interviewees in the sense of correcting a service failure:

... it gives us a second chance to recover and "wow" the experience of a complaining guest. (P8)

Complains also gave hotels the opportunity to evaluate service make more wide-spread and long-term adjustments to service delivery:

... it is really important for us to have guests' feedback, it helps us on things to like, what to correct and how to actually treat our guests. (P9)

Participants also believed that complaints and how they are managed impact the image of the hotel and could improve guest loyalty and word of mouth:

[Complaint management] ... is the art of every hotel's operation, because it affects the hotel's image. . . because of image, and loyalty and reviews on TripAdvisor, on the social media, that's why it's so important. (P3) 
The second set of questions addressed how complaints are handled by participants' hotels and revealed three themes: training; company culture; tracking.

Training. While participants felt it was important that all members of staff should attend complaint management training, ten out of the eleven stated that trainings were only offered to supervisors. While role plays were common delivery methods, the variation in trainings were notable, with some trainings mainly focussed on the company's SOPs:

...we read through the SOP, like I gave it my feedback about the situation, which can happen. (P5)

While others were more extensive and also included non-verbal training:

[Training covered] ...posture and as well how non-nonverbal language so how you display calm how you display empathy... (P3)

These trainings frequently addressed the hotel's standards and procedures to ensure a consistent complaint management process, although whether they are standardised into SOPs was debated.

there are procedures which are, which, about which we are all trained. So, never say no to a guest, always give alternatives and control yourself, stay in self [control], so maintain calmness. (P3)

... no SOPs in place, however there is a general pattern where complaint is received ... the first thing to do is to apologize and try to find out what went wrong. (P8)

Company culture. Participants emphasised the importance of company culture in handling complaints to move beyond the standards:

SOPs are very, very straightforward, very strict, very systematic, but we try our best to give a personal touch or feeling from a five-star hotel. (P10)

While empowering employees was mentioned by the majority of participants, it was not provided as a main method of handling complaints, although the reliance on personal experience was cited, but was affected by the company's culture of empowerment:

... there are some scenarios that we can work on based on our experience. . . (P9)

Tracking. Most participants also emphasised the importance of having a system in place to evaluate complaints. First, to ensure they were resolved:

... we log all the complaints in the [Hotel Complaint Management System]. And we do follow up from shift to another shift... (P6)

Secondly, to ensure that such incidents were not repeated:

... everything can be recovered. However, if you repeat the same mistake over and over again that will, yeah, turn them off completely from. . . from the brand. (P4)

\section{Ways to improve complaint management processes}

The third set of questions explored the participant's perceptions on how the complaint management process could be improved. The themes of training and company culture arose, with empowerment being a notable sub-theme of both training and company culture.

To help with complaint management, participants believed that it was important to provide specific standards and trainings to support employees:

We should have more frequent trainings because once you have, you're not receiving training sometimes you just become like, you need to refresh your mind, right? (P9) 
From a corporate culture perspective, participants recommended a change in internal complaint policies to ensure a more careful evaluation of the complaint and response, reducing the likelihood to recurring complaints or customers complaining for free upgrades, etc.:

[Hotels should not] compensate without getting to the root of the problem because the problem can happen again. (P8)

Participants described the need to train staff to ensure they had the knowledge they needed to empower them to solve customer complaints:

I always wanted that our employees, especially frontline employees, are knowledgeable enough. (P6)

In other cases, empowerment referred to the requirement of ensuring an appropriate corporate culture to place more trust in employees:

So, what is important as well as how you operationally built the rapport with your colleagues, right not to have a fear base right? The operation that you can't, I mean, you need to let them understand that mistakes happen at all. . . at all levels, but the way you're going to handle it, makes a difference. (P4)

\section{Impacts on complaint management}

The last set of questions asked what factors impact the management of complaints. In total, two main themes arose of customer condition and staff condition. Staff further broke down into their attitude and demographics. While participants did describe the impact of staff demographics, it was a general observation. When participants were probed on the impact of gender, nationality, age and education, as per literary justification, more detailed insights arose.

Almost half, on the other hand, described the personality of the complaint handler and their experience:

I think the personality also can be a huge impact on the guest. . (P6)

So, let's say I've handled the guests from maybe Americas right, or you've handled the guest from the Middle East. So, when you're hired, they would look into that because you have built your experience, expertise in a way as well in knowing the guest. (P4)

Participants also described the condition of staff when they were handling a particular complaint:

You can see like some of your team members, they can be really the best, but they have some issues at home and they're a little bit frustrated and they come to [work, then], for sure they can't, the same level of service which they used to deliver in the past. (P5)

When probed more directly, participants commented on the impact of gender, nationality, age, and education on how complaints were handled.

Gender. While four interviewees did not see gender as significant factor, the majority felt that there was an influence. Interviewees highlighted that staffs' approach would differ based on their gender:

each of the female managers I know will be calm. . but men it's not like that. . (P1)

men are better with dealing with aggressive complaints, they are more direct in their approach and professional. Women are more likely to involve emotions... (P8)

A total of four participants also spoke about how the opposing gender would have an impact on complaint management behaviour.

It's an observation and it's a personal experience that you see that if it's a lady who's complaining and there's another lady in front of her you can feel that the tension will be higher. If a gentleman and 
IHR

36,2

a gentleman, the tension would be higher. However, if you have two different genders, the things would be different. (P11)

A total of three interviewees, interestingly all women, also believed that the perception of gender would also impact the process of complaining as well as complaint handling:

some other guests would not prefer talking to a woman, some would prefer talking to men... (P9)

Nationality. This characteristic showed more consensus amongst the participants, with eight believing that cultural aspects impact the complaint handling process inadvertently or not:

who they are like, you know, their background? There's so much factor their age, their religion, their environment, like their culture. There's a lot of cultural you know, like, values and links involved. (P1)

Sometimes, this was put down to issues such as misunderstandings and language barriers "I have seen that sometimes for language barriers. .." (P3), which allowed for different degrees of understanding or directness "go. . straight to the point" (P1).

Seven interviewees also believed that the guest perception of nationality had an impact "then I talk to them in Arabic and they know that I'm Lebanese, then, oh my God, like 70\% of the problem vanished" (P11). In total, three participants also believed that nationality allowed them to understand guest needs better "if you are the same nationality or from the same region or close to it, you might understand it better" (P4).

A total of three participants believed that the impact of nationality gradually reduces when you become more experienced, emphasised with P1 stating "it's based on your experience are going to you're going to change your vision of thinking and you're going to add up your management style to becoming more like, I would say, international. ..."

Age. When describing the impact of age, most participants felt that age did have an impact on the style of managing complaints. One manner through which age was perceived to have an impact was the rate of a resolution "there is a very huge chance of the younger generation doing it a bit differently. And it would be a bit quicker." (P2). In another perspective, participants felt that younger staff would be able to "more emotional engage with a guest..." and offer more innovative solutions:

We need a new generations or younger leadership with a fresh mind, with creative mind and come up with new ideas, innovations, all those things... (P6)

On the other hand, several participants highlighted that older staff would have an advantage in dealing with complaints due to greater experience:

Older people are likely to have more experience, more maturity and better patience so their approach is more structured and less empathetic. (P8)

Education. While five participants believed that experience is more important and had a greater impact on complaint management processes than education, six believed that education has an effect on the knowledge of the individual "education gives you an insight of exactly how our hotel completely worked" (P10).

Additionally, four interviewees highlighted that education impacts complaint handling because of the skills gained.

There was something about using the computer, talking to the people, your tone, your elegance, something that I didn't need to teach you compared to someone else which was just coming, coming to work without any of this. Okay, so education is important, is definitely important. (P3)

Finally, three interviewees believed that education impacts complaint management through the ability of educated individuals to better implement theories. 
You have newer case studies that you're looking into. There are newer examples that you are looking at, you have you're on the job training just like yourself when you were at [hotel name]. So, this gives you a better exposure to manage and to handle complaints. (P2)
Complaint management behaviour

\section{Discussion}

\section{Complaint management}

In terms of defining complaint management, consistency existed between the literature and interview results with the essence being solving guest problems in response to a service failure (McCole, 2004; Ogbeide et al., 2017) and identifying guest needs (Sturman et al., 2011).

Participants generally felt that guests complained to receive some form of compensation. While this result is supported in the literature (Chan et al., 2017), participants felt that the compensation was frequently the purpose of the complaint, not only to offset some economic loss (Chan et al., 2017). This adds to the complexity of complaint management because of the additional requirement to assess the genuineness of complaints. Furthermore, it enhances the need to carefully track the resolution of complaints to better understand if false complaints are being raised and either their resolution, or what compensation was offered. In cases where compensation is offered without the appropriate investigation, it can develop a culture of "complaining for freebies", or even customers threatening public complaints - through online review channels - for compensation. Careful tracking of complaints can help control and, hopefully, prevent such eventualities.

Other reasons participants offered for why guests complained have received similar consideration in the literature, mostly around a business' inability to meet guest expectations (McCole, 2004; Sturman et al., 2011) or as a general expression of dissatisfaction (Ogbeide et al., 2017).

One of the most commonly cited consequences of guest complaints from participants was the impact upon operations, notably, the stress placed upon staff. While existing literature has suggested that employees do not always think complaints are positive for a business (Traut-Mattausch et al., 2015), the negative impact upon staff has not been fully explored.

Several other impacts of complaints were identified by participants, which have been discussed in the literature, reflecting greater consensus between this sample and extant literature. Such impacts included the ability to improve service (Krishna et al., 2014; McCollough et al., 2000; Stauss and Schoeler, 2004; Taleghani et al., 2011), promoting guest loyalty (Stauss and Schoeler, 2004), notably through the service recovery paradox (Maxham and Netemeyer, 2002; Michel and Meuter, 2008; Ok et al., 2007; Smith and Bolton, 1998), and influencing word-of-mouth (Dinnen and Hassanien, 2011; Janjua, 2017; Stauss and Schoeler, 2004).

\section{Existing infrastructure of complaint management}

When asked about the existing systems used to handle complaints, participants were able to clarify several points which have been previously addressed in the literature. Chief amongst these were trainings used to educate staff on the ideal complaint management process, which has become particularly important as more businesses look to empower their staff (Dinnen and Hassanien, 2011; Ogbeide et al., 2017; Zhang and Geng, 2019). According to the findings, staff are trained through role plays, on SOPs and complaint theory, and given non-verbal action training to provide staff with the necessary skills to handle complaints (Ogbeide et al., 2017). When it comes to training on basic procedures, there are guidelines on how employees should implement their interpersonal skills to enhance the experience. Additionally, there are complaint management systems in place which standardise how complaints are processed and recorded. Finally, empowerment training allows for guidelines in terms of what sort of 
IHR

36,2

212

compensation can be provided by employees at different levels of management. This finding is in line with the proposed model of a standardised complaint management system by Phabmixay et al. (2019) seen in Figure 1. While the model has been proposed for the manufacturing industry, it can be seen as a process that is being implemented in five-star hotels in in Dubai. This is an important finding as it becomes evident that standardised complaint management systems can enhance the processes even in the hotel industry, one that is known for personalisation. Further academic research and industrial practice could, therefore, draw on such complaint management systems to help develop more robust complaint management processes. From the findings, however, it is evident that no property has mastered the art of all three guidelines: behavioural; procedural and outcome. This, however, can be seen as the start of complaint handling standardisation in hotels, where Phabmixay et al.'s (2019) model can improve their current processes.

\section{Improving the complaint management processes}

Recommendations provided by hoteliers include clearer definition of rules, implementing standards and better empowerment. These recommendations would provide a more mechanistic (Phabmixay et al., 2019) and clear approach towards complaint management (Davidow, 2003; Homburg et al., 2010).

Additionally, hoteliers also expressed a need for more trust in colleagues, better product knowledge and training as things which would improve the complaint management processes in hotels. As discussed earlier, empowerment of front-line employees and the broadening of their job roles to include complaint management is a relatively new concept in hotels (Dinnen and Hassanien, 2011; Ogbeide et al., 2017; Zhang and Geng, 2019), possibly explaining the lack of extensive complaint management training.

Findings of this study also emphasise the importance of better recruitment processes as interviewees believed that the personality, lifestyle, mental health and the type of experience an individual has had have an impact on the complaint management behaviour. Industry can consider this as a long-term recommendation which can improve the consistency of the service that they provide in terms of complaint management.

\section{Demographics impacts on complaint management}

Throughout extant literature, some demographic influence upon complaint management behaviour has been alluded to or could be suggested, particularly in terms of gender (ChungHerrera et al., 2010; Gruber et al., 2009; McColl-Kennedy et al., 2003), nationality (Defranco et al., 2005; Emir, 2011; Ngai et al., 2007; Prayag and Ryan, 2012), age (Chung-Herrera et al., 2010; Kasabov and Hain, 2014) and education levels (Ngai et al., 2007; Sujithamrak and Lam, 2005). The results of this study provided a direct connection between these traits and the methods of complaint management. Academically, this provides further areas of analysis and consideration which should be explored to better understand how demographics influence complaint handling, conflict resolution or crisis management. Practically, more specific advice can be offered in terms of training to provide more consistent and accurate service.

Gender. According to the findings of the study, gender impacts the approach that a hotelier takes to handling complaints, similar to the conclusions of Chung-Herrera et al. (2010). Indirectly, this finding coincides with those of Gruber et al. (2009), which suggest that women and men had differing expectations from service failure scenarios. Additionally, according to Mukudan and Zakkariya (2018), male and female managers adopted different management styles when coming in contact with conflict, coinciding with the findings of this study.

Findings of this study also revealed that the way of speaking differed due to the gender of the individual with some believing that men were more direct and women were more emotionally involved, similar to the findings of McColl-Kennedy et al. (2003), who found that 
women wanted a more socially involved service recovery experience than men. However, participants also argued that men are equally able to emotionally engage with guests as women are. Interviewees believed that men can also be as empathetic of the situation as women. This finding opposes the findings of Carmona et al. (2018) which state that women can adopt masculine and feminine leadership styles whereas men were more focused on one particular style of leadership. This difference in findings can be attributed to the fact that the authors of the study emphasised that it could be applied in male-dominated societies. While Dubai's population may be more male dominated, the hospitality industry in Dubai does not seem to follow the same pattern, due to the high number of expatriates working in the sector.

Nationality. The culture of an individual was highlighted as a factor which influences complaint management behaviour. Interviewees believed that nationality impacts the culture and background of individuals, which leads to differences in complaint handling. Snaebjornsson and Edvardsson (2012) support this finding, suggesting that influences of nationality and ethnicity on leadership are particularly relevant in multicultural societies, and these influences are visible in the leadership style. Additionally, Nazarian and Atkinson (2013) and Ngai et al. (2007) also indicated that the dimensions of national culture, such as uncertainty avoidance and individualism, (Hofstede et al., 2010) had an impact on behaviour, something that was found in this study with participants emphasising that behaviour was impacted by the nationality of individuals. However, participants also argued that, over time and with experience, this difference would reduce as individuals adopt a more international mindset. This is an aspect that existing literature does not identify.

Interviewees also identified understanding needs as something which change based on nationality, highlighting that individuals from the same country or region as the guest could better understand guests' needs (Defranco et al., 2005; Emir, 2011; Prayag and Ryan, 2012). There needs to be further focus on the impact of language barriers on complaint management experiences both from the perspective of guests and hoteliers as there is currently limited research on this; however, it was something which was emphasised by participants as a key element which impacts the experience.

Age. Results of this study highlighted that age impacts the speed of resolution, the type of resolution and the way of talking of an individual. Interviewees believed that younger individuals are more likely to be empathetic in their approach, with quicker and more creative resolutions. While Kasabov and Hain (2014) found similar results showing that Generation Y were observed to be more empathetic towards the situation, results of this study contrast with those of Kang and Hillery (1998), which state that younger customers placed importance on money. Monetary compensation is the least creative approach available, and the results of this study suggest that younger individuals are more creative in their approach.

The age of guests was also seen as something that would impact the complaint management process. However, this opposes the findings of Chung-Herrera et al. (2010), which found that guests did not think that age of the service provider had an impact on the process. This difference may be because complaint handlers are more able to adapt their style to the age of the guest, limiting this inconsistency from being visible to customers.

Education. This study revealed that education impacts the skills and knowledge of an individual, which are vital for complaint management. Interviewees of this study highlighted that formal education gives individuals the knowledge to use systems, which are in place, and have the know-how of how the hotel operation works, which improves the complaint management process indirectly.

On the other hand, some participants also believed that experience is more important than education when it comes directly to complaint handling. This is in line with literature which revealed that employers prefer to recruit individuals who had work experience over those who had only theoretical knowledge and conceptual understanding (Kong, 2015). It is
Complaint management behaviour 
IHR

36,2 important to note, however, that interviewees highlighted that better recruitment is needed with better processes which address not only education and experience.

\section{Conclusion}

This study has looked at the impact of staff demographics on complaint management behaviours in five-star hotels in Dubai through a qualitative approach. This research paper has established that complaint management is an extremely important, and sometimes overlooked, aspect of the hotel's operation as it has an impact on guest loyalty and overall competency of the hotel (Cai and Chi, 2018; Chan et al., 2017; Krishna et al., 2011). Additionally, it has also discovered that staff demographic factors have an impact on the complaint management behaviour and the overall process (Chung-Herrera et al., 2010). With demographic factors impacting the needs, wants and priorities of individuals (Chiang and Birtch, 2008; Sourouklis and Tsagdis, 2013) and the increased diversity in the UAE and the hospitality industry (Gajjar and Okumus, 2018; Lee and Lee, 2012), there was a need for research in this topic.

Through 11 semi-structured, in-depth interviews, complaint management was seen to be a process of handling complaints and solving guest problems, which may occur as guests complain about needing compensation, dissatisfaction or needs not being met. Current infrastructure of complaint management allows for demographic differences to play a role with basic procedures such as explaining, offering solutions and listening listed as key procedures. When it comes to required processes, a range of recommendations hinted towards a more standardised, mechanistic and defined approach, which considers factors such as the lifestyle, mental health and personality of employees. Current demographic impacts were identified with all factors having somewhat of an impact on way of speaking. Gender was seen to be a factor impacting approach to the handling of complaints and the perception of gender playing a role in the process. Nationality impacted the understanding of needs and culture of staff. Age was seen to impact type and speed of resolution. Finally, education was said to have an impact on the knowledge and skills of an individual.

\section{Limitations}

Throughout the study, various limitations were identified. When it came to the methodology and data collection, due to the COVID-19 pandemic, various aspects were impacted. First, many potential participants were no longer able to be interviewed as they either did not have time or had been laid off and were not in the mindset to participate in the study. Moreover, as it was unsafe to go out and many hotels were closed, all participants had to be found through personal contacts or LinkedIn. Due to the fluctuations in connection some parts of the interview were not properly recorded, meaning more time had to be spent during transcription to understand what was being said. Finally, as the study looks at demographics and not all individuals of all demographics were interviewed, this may reduce the generalisation of the findings. However, it is not feasible to do so, and the interviewees were selected as they would be able to provide insight that does not only consider their demographic. It is impossible to segregate the answers of their individuals from their demographics, but the questions were structured in a way which would limit this from happening by asking interviewees about trends they have noticed in their team as opposed to their personal experience only.

\section{Recommendations for further research}

Based on this study and the process of the study, the main recommendation provided for future study is to take a quantitative approach on this study to understand how different 
demographics impact the complaint management behaviour of staff and if these findings coincide with the findings of this study. Additionally, further research can address how individuals' complaint management behaviour is impacted by their demographics through a different approach, such as observations, which would allow for more candid results. By observing individuals who were handling complaints in real-life would remove the aspect of bias which cannot be omitted when responding to questions. Further research can also be expanded in terms of the number of participants involved, the geographic range covered, the hotel class included and the demographics which are considered. Additionally, further research can also be done to understand what the customers' perspectives on demographic factors and their impact on complaint handling are.

\section{Recommendations for industry practitioners}

The recommendation to corporates and individuals responsible for the implementation of standards would be to consider a more standardised approach to complaint management, which allows the staff to act based on their demographics whilst still maintaining consistency of service. As some participants explained, hotels can consider having a page on the company intranet with a list of common complaints, how they have been solved in the past and what the appropriate solution or compensation would be for this complaint. Additionally, learning and development (L\&T) departments in hotels should increase the frequency of complaint management trainings with tests or quizzes at the end of the training, which will push individuals to pay more attention and participate actively in the trainings. Hotels that have not already done so should clarify the empowerment guidelines and make each member of staff aware of what their empowerment is. Hotels could also implement a system to reward colleagues who have managed to delight guests and turn around complaints to satisfaction as a motivator for front-line colleagues to handle complaints as opposed to forwarding them to their managers or seniors. The HR department should also consider altering the recruitment process in a way to better understand the individual and understand if the individual would fit with the company culture based on their personality and other factors. Middle managers should also motivate their subordinates to handle complaints. The understanding of demographic differences should be used by higher management and middle managers for major complaints that were not handled on the spot. It should be used to match the correct employee with the type of guest who is complaining and the type of complaint that is being made so that the demographics can be used to the advantage of the hotel and the guest. Following these recommendations will allow hotels to be more competitive through effectively handling complaints.

\section{References}

Bambauer-Sachse, S. and Rabeson, L.E. (2015), "Service recovery for moderate and high involvement services”, Journal of Services Marketing, Vol. 29 No. 5, pp. 331-343.

Boella, M.J. and Goss-Turner, S. (2013), Human Resource Management in the Hospitality Industry: An Introductory Guide, 9th ed., Routledge, Taylor \& Francis Group, London.

Braun, V. and Clarke, V. (2006), "Using thematic analysis in psychology", Qualitative Research in Psychology, Vol. 3 No. 2, pp. 77-101.

Bryman, A. and Bell, E. (2015), Business Research Methods, 4th ed., Oxford University Press, Cambridge, New York, NY.

Cai, R. and Chi, C.G.Q. (2018), "The impacts of complaint efforts on customer satisfaction and loyalty", The Service Industries Journal, Vol. 38 Nos 15-16, pp. 1095-1115.

Cambra-Fierro, J., Melero-Polo, I. and Javier Sese, F. (2016), "Can complaint-handling efforts promote customer engagement?”, Service Business, Vol. 10 No. 4, pp. 847-866. 
IHR

36,2

\section{6}

Carmona, S., Ezzamel, M. and Mogotocoro, C. (2018), "Gender, management styles, and forms of capital”, Journal of Business Ethics, Vol. 153 No. 2, pp. 357-373.

Chan, G.S.H., Tang, I.L.F. and Sou, A.H.K. (2017), "An exploration of consumer complaint behavior towards the hotel industry: case study in Macao", International Journal of Marketing Studies, Vol. 9 No. 5, p. 56.

Chattopadhyay, P., Tluchowska, M. and George, E. (2004), "Identifying the ingroup: a closer look at the influence of demographic dissimilarity on employee social identity", The Academy of Management Review, Vol. 29 No. 2, p. 180.

Chaudhary, R. and Rangnekar, S. (2017), "Socio-demographic factors, contextual factors, and work engagement: evidence from India”, Emerging Economy Studies, Vol. 3 No. 1, pp. 1-18.

Cheng, S. and Lam, T. (2008), "The role of the customer-seller relationship in the intention of the customer to complain: a study of Chinese restaurateurs", International Journal of Hospitality Management, Vol. 27 No. 4, pp. 552-562.

Chiang, F.F.T. and Birtch, T.A. (2008), "Achieving task and extra-task-related behaviors: a case of gender and position differences in the perceived role of rewards in the hotel industry", International Journal of Hospitality Management, Vol. 27 No. 4, pp. 491-503.

Chung-Herrera, B.G., Gonzalez, G.R. and Hoffman, K.D. (2010), "When demographic differences exist: an analysis of service failure and recovery among diverse participants", Journal of Services Marketing, Vol. 24 No. 2, pp. 128-141.

Cook, S. (2011), Customer Care Excellence: How to Create an Effective Customer Focus, 6th ed., Kogan Page, London, Philadelphia.

Cooper, D.R. and Schindler, P.S. (2008), Business Research Methods, 10th ed., McGraw Hill, New York.

Creswell, J.W. and Creswell, J.D. (2018), Research Design: Qualitative, Quantitative, and Mixed Methods Approaches, 5th ed., SAGE, Los Angeles.

Davidow, M. (2003), "Organizational responses to customer complaints: what works and what doesn't", Journal of Service Research, Vol. 5 No. 3, pp. 225-250.

Defranco, A., Wortman, J., Lam, T. and Countryman, C. (2005), "A Cross-cultural comparison of customer complaint behavior in restaurants in hotels", Asia Pacific Journal of Tourism Research, Vol. 10 No. 2, pp. 173-190.

Dinnen, R. and Hassanien, A. (2011), "Handling customer complaints in the hospitality industry", International Journal of Customer Relationship Marketing and Management, Vol. 2 No. 1, pp. 69-91.

DTCM (2021), "Dubai tourism performance report", Dubai Tourism, available at: https://www. dubaitourism.gov.ae/en/research-and-insights/tourism-performance-report-february-2021 (accessed 13 April 2021).

Dubai Statistics Center (2021), "Dubai statistics center", Dubai Statistics Center, available at: https:// www.dsc.gov.ae/en-us\# (accessed 22 February 2017).

Dutt, C.S. and Ninov, I. (2017), “Expatriates' learning: the role of VFR tourism”, Journal of Hospitality and Tourism Management, Vol. 31, pp. 253-264.

Emir, O. (2011), "Customer complaints and complaint behaviours in Turkish hotel restaurants: an application in Lara and Kundu areas of Antalya", African Journal of Business Management, Vol. 5 No. 11, pp. 4239-4253.

Estelami, H. (2000), "Competitive and procedural determinants of delight and disappointment in consumer complaint outcomes", Journal of Service Research, Vol. 2 No. 3, pp. 285-300.

Farazad, K. (2020), "How to maintain consumer relationship during COVID-19", Hospitality Net, 8 May, available at: https://www.hospitalitynet.org/opinion/4098564.html (accessed 11 April 2021).

Gajjar, T. and Okumus, F. (2018), "Diversity management: what are the leading hospitality and tourism companies reporting?”, Journal of Hospitality Marketing \& Management, Vol. 27 No. 8, pp. $905-925$. 
Galletta, A. (2016), Mastering the Semi-structured Interview and beyond: From Research Design to Analysis and Publication. doi: 10.18574/nyu/9780814732939.001.0001 (accessed 11 April 2021).

Gelbrich, K., Gäthke, J. and Grégoire, Y. (2015), "How much compensation should a firm offer for a flawed service? An examination of the nonlinear effects of compensation on satisfaction", Journal of Service Research, Vol. 18 No. 1, pp. 107-123.

Gruber, T., Szmigin, I. and Voss, R. (2009), "Handling customer complaints effectively: a comparison of the value maps of female and male complainants", Managing Service Quality: An International Journal, Vol. 19 No. 6, pp. 636-656.

Hart, C.W., Heskett, J.L. and Sasser, W.E. Jr (1990), "The profitable art of service recovery", Harvard Business Review, available at: https://hbr.org/1990/07/the-profitable-art-of-service-recovery (accessed 11 April 2021).

Hofstede, G.H., Hofstede, G.J. and Minkov, M. (2010), Cultures and Organizations: Software of the Mind: Intercultural Cooperation and its Importance for Survival, 3rd ed., McGraw-Hill, New York.

Homburg, C., Fürst, A. and Koschate, N. (2010), "On the importance of complaint handling design: a multi-level analysis of the impact in specific complaint situations", Journal of the Academy of Marketing Science, Vol. 38 No. 3, pp. 265-287.

Islam, G. (2014), "Social identity theory", in Teo, T. (Ed.), Encyclopedia of Critical Psychology, Springer New York, New York, NY, pp. 1781-1783.

Janjua, Q.R. (2017), "Service failures and consumer responses: exploring the antecedents of consumer dissatisfaction and propensity to complain", Business and Economic Review, Vol. 9 No. 4, pp. 23-48.

Jennings, G. (2010), Tourism Research, Wiley Australia, Milton, Qld, Vol. 2.

Kandampully, J., Zhang, T. and Jaakkola, E. (2018), "Customer experience management in hospitality: a literature synthesis, new understanding and research agenda", International Journal of Contemporary Hospitality Management, Vol. 30 No. 1, pp. 21-56.

Kang, J. and Hillery, J. (1998), "Older salespeople's role in retail encounters", The Journal of Personal Selling and Sales Management, Taylor \& Francis, Ltd., Vol. 18 No. 4, pp. 39-53.

Kasabov, E. and Hain, T. (2014), "Cross-generational perceptions and reactions during service recovery", The Service Industries Journal, Vol. 34 No. 1, pp. 71-87.

Kong, A.P. (2015), "The dilemma facing higher education and industry in tourism and hospitality", Springer Plus, Vol. 4 No. S2, pp. 2193-1801, -4-S2-P2.

Krishna, A., Dangayach, G.S. and Jain, R. (2011), "Service recovery: literature review and research issues", Journal of Service Science Research, Vol. 3 No. 1, p. 71.

Krishna, A., Dangayach, G.S. and Sharma, S. (2014), "Service recovery paradox: the success parameters", Global Business Review, Vol. 15 No. 2, pp. 263-277.

Lee, C. and Lee, J.W. (2012), "Analysis of the relationships between the hospitality workforce and jobsatisfaction factors according to age, gender, native language and racial-ethnicity", Journal of Tourism and Hospitality, Vol. 1 No. 5, doi: 10.4172/2167-0269.1000104.

Lewis, B.R. and McCann, P. (2004), "Service failure and recovery: evidence from the hotel industry", International Journal of Contemporary Hospitality Management, Vol. 16 No. 1, pp. 6-17.

Maxham, J.G. and Netemeyer, R.G. (2002), "A longitudinal study of complaining customers' evaluations of multiple service failures and recovery efforts", Journal of Marketing, American Marketing Association, Vol. 66 No. 4, pp. 57-71.

McCole, P. (2004), "Dealing with complaints in services", International Journal of Contemporary Hospitality Management, Vol. 16 No. 6, pp. 345-354.

McColl-Kennedy, J.R., Daus, C.S. and Sparks, B.A. (2003), "The role of gender in reactions to service failure and recovery", Journal of Service Research, Vol. 6 No. 1, pp. 66-82.

Complaint management behaviour 
IHR

36,2

\section{8}

McCollough, M.A., Berry, L.L. and Yadav, M.S. (2000), "An empirical investigation of customer satisfaction after service failure and recovery", Journal of Service Research, Vol. 3 No. 2, pp. 121-137.

Michel, S. and Meuter, M.L. (2008), “The service recovery paradox: true but overrated?", International Journal of Service Industry Management, Vol. 19 No. 4, pp. 441-457.

Mukundan, S.P. and Zakkariya, K.A. (2018), "Gender role identity and conflict management styles of managers in the service sector", Vol. 7 No. 1, p. 9.

Nam, K., Dutt, C.S., Chathoth, P., Daghfous, A. and Khan, M.S. (2020), "The adoption of artificial intelligence and robotics in the hotel industry: prospects and challenges", Electronic Markets, pp. 454-468, doi: 10.1007/s12525-020-00442-3.

Nazarian, A. and Atkinson, P. (2013), "Impact of culture on leadership style", The Case of Iranian Organisations, Vol. 28 No. 6, pp. 770-777.

Newnham, M.P. and Dutt, C.S. (2021), "Knowledge sharing among hotel workers in Dubai, UAE", Journal of Human Resources in Hospitality and Tourism (In press).

Ngai, E.W.T., Heung, V.C.S., Wong, Y.H. and Chan, F.K.Y. (2007), "Consumer complaint behaviour of Asians and non-Asians about hotel services: an empirical analysis", European Journal of Marketing, Vol. 41 Nos 11-12, pp. 1375-1391.

Nowell, L.S., Norris, J.M., White, D.E. and Moules, N.J. (2017), “Thematic analysis: striving to meet the trustworthiness criteria", International Journal of Qualitative Methods, Vol. 16 No. 1, 160940691773384 .

Ogbeide, G.C.A., Böser, S., Harrinton, R.J. and Ottenbacher, M.C. (2017), "Complaint management in hospitality organizations: the role of empowerment and other service recovery attributes impacting loyalty and satisfaction", Tourism and Hospitality Research, Vol. 17 No. 2, pp. 204-216.

Ok, C., Back, K.J. and Shanklin, C.W. (2007), "Mixed findings on the service recovery paradox", The Service Industries Journal, Vol. 27 No. 6, pp. 671-686.

Olsen, J.E. and Martins, L.L. (2012), "Understanding organizational diversity management programs: a theoretical framework and directions for future research", Journal of Organizational Behavior, Vol. 33 No. 8, pp. 1168-1187.

O'Gorman, K. and MacIntosh, R. (2016), Research Methods for Business and Management: A Guide to Writing Your Dissertation, Good Fellow Publishers, Oxford.

Phabmixay, C.S., Rodríguez-Escudero, A.I. and Rodríguez-Pinto, J. (2019), "Benefits from the standardisation of the complaint management system", Total Quality Management and Business Excellence, pp. 737-757.

Prayag, G. and Ryan, C. (2012), "Visitor interactions with hotel employees: the role of nationality", in Cave, J. (Ed.), International Journal of Culture, Tourism and Hospitality Research, Vol. 6 No. 2, pp. 173-185.

Rizvi, M. (2021), “Covid-19: UAE records world's second-highest hotel occupancy rate in 2020”, Khaleej Times, 10 April, available at: https://www.khaleejtimes.com/news/covid-19-uae-records-worldssecond-highest-hotel-occupancy-rate-in-2020 (accessed 13 April 2021).

Saldaña, J. (2016), The Coding Manual for Qualitative Researchers, 3rd ed., SAGE, Los Angeles, London.

Sarpong, S. (2016), "The service industry and the 'moment of truth': the quest for the holy grail", Athens Journal of Tourism, Vol. 3 No. 1, pp. 25-40.

Schindler, P.S. (2019), Business Research Methods, 13th ed., McGraw-Hill Education, New York, NY.

Singh, V., Jain, A. and Choraria, S. (2016), "Exploring the role of complaint handling among complaining consumers", Vision: The Journal of Business Perspective, Vol. 20 No. 4, pp. 331-344.

Smith, A.K. and Bolton, R.N. (1998), "An experimental investigation of customer reactions to service failure and recovery encounters: paradox or peril?”, Journal of Service Research, Vol. 1 No. 1, pp. $65-81$. 
Snaebjornsson, I.M. and Edvardsson, I.R. (2012), "Gender, nationality and leadership style: a literature review", International Journal of Business and Management, Vol. 8 No. 1, p. 89.

Sourouklis, C. and Tsagdis, D. (2013), "Workforce diversity and hotel performance: a systematic review and synthesis of the international empirical evidence", International Journal of Hospitality Management, Vol. 34, pp. 394-403.

Stauss, B. and Schoeler, A. (2004), "Complaint management profitability: what do complaint managers know?”, Managing Service Quality: An International Journal, Vol. 14 Nos 2-3, pp. 147-156.

Stone, M. (2011), "Literature review on complaints management", Journal of Database Marketing and Customer Strategy Management, Vol. 18 No. 2, pp. 108-122.

Sturman, M.C., Corgel, J.B., Verma, R. and Cornell University (Eds), (2011), The Cornell School of Hotel Administration on Hospitality: Cutting Edge Thinking and Practice, Wiley, Hoboken, N.J.

Sujithamrak, S. and Lam, T. (2005), "Relationship between customer complaint behavior and demographic characteristics: a study of hotel restaurants' patrons”, Asia Pacific Journal of Tourism Research, Vol. 10 No. 3, pp. 289-307.

Susskind, A.M. (2010), "Guest service management and processes in restaurants: what we have learned in fifty years", Cornell Hospitality Quarterly, available at: https://ecommons.cornell.edu/ handle/1813/71957 (accessed 12 April 2021).

Tag-Eldeen, A. (2018), "Assessing the impact of complaints management system in hospitality organizations in Egypt: a customer-organization perspective", Ottoman Journal of Tourism and Management Research, Vol. 3 No. 3, pp. 306-317.

Tajfel, H. (Ed.), (2010), Social Identity and Intergroup Relations, 1. paperback printing. Cambridge Univ. Press [u.a.], Cambridge.

Taleghani, M., Largani, M.S., Gilaninia, S. and Mousavian, S.J. (2011), "The role of customer complaints management in consumers satisfaction for new industrial enterprises of Iran", International Journal of Business Administration, Vol. 2 No. 3, p. 140.

Traut-Mattausch, E., Wagner, S., Pollatos, O. and Jonas, E. (2015), "Complaints as starting point for vicious cycles in customer-employee-interactions", Frontiers in Psychology, Vol. 6, doi: 10.3389/ fpsyg.2015.01454.

Van Vaerenbergh, Y. and Orsingher, C. (2016), "Service recovery: an integrative framework and research agenda", Academy of Management Perspectives, Vol. 30 No. 3, pp. 328-346.

Zhang, M. and Geng, R. (2019), "Empowerment in service recovery: the role of self-regulation process of frontline employee", Management Decision, Vol. 58 No. 5, pp. 828-843.

\section{Corresponding author}

Christopher S. Dutt can be contacted at: chris.s.dutt@gmail.com

For instructions on how to order reprints of this article, please visit our website:

www.emeraldgrouppublishing.com/licensing/reprints.htm

Or contact us for further details: permissions@emeraldinsight.com 